\title{
Prevalence, pattern and predictors of premenstrual syndrome (PMS) and premenstrual dysphoric disorder (PMDD) among college girls
}

\author{
Anitha Durairaj, Rathna Ramamurthi \\ Correspondence: Dr. Anitha Durairaj, Assistant professor, Department of Obstetrics and \\ Gynaecology, Velammal Medical College Hospital and Research Institute, Madurai, Tamil \\ Nadu, India. Email - dranithasrinidhi@gmail.com
}

Distributed under Attribution-NonCommercial-ShareAlike 4.0 International (CC BY-NC-SA 4.0)

\begin{abstract}
Objective - To determine the prevalence, pattern and predictors of PMS and PMDD among college girls of South India. To identify the knowledge and attitude of college girls with PMS and PMDD. Methodology - A cross sectional questionnaire study based on Premenstrual Syndrome Screening Tool was conducted among the college student of Madurai, Tamilnadu. Results - The prevalence of moderate to severe PMS was $14.3 \%$ and PMDD was 3.7\%. The commonest premenstrual symptom among college girls was fatigue/lack of energy, in the moderate to severe PMS category was anger and in the PMDD category was anxiety. Impairment of college efficiency or productivity was seen in $82.66 \%$ and $100 \%$ of students with moderate to severe PMS and PMDD respectively. The prevalence of moderate to severe PMS and PMDD correlated significantly with the mean age, education, heavy menstrual flow, dysmenorrhoea and family history of PMS and $85.6 \%$ college students with moderate to severe PMS and PMDD didn't perceived their symptoms as abnormal and only $16.4 \%$ had a physician consultation. Conclusion - PMS and PMDD are prevalent among substantial proportion of college girls with a significant negative influence on academic performance, emotional well being and behaviour. Strategies should be adopted in the college health program for timely recognition and management of PMS and PMDD in college girls.
\end{abstract}

Keywords: College girl, premenstrual syndrome, PMDD.

Although menstruation is bounded by myths and taboos in our society, menstrual disorders have gained attention. Nevertheless, premenstrual disorders (PMD) are still under recognised. PMD is a psychoneuroendocrine problem of unknown etiology. It is characterized by somatic, emotional and behavioral symptoms occurring in the luteal phase of the menstrual cycle. International Society for Premenstrual Disorders (ISPMD) consensus classified PMD into core PMD and variant $\mathrm{PMD}^{1}$. Premenstrual syndrome (PMS) and premenstrual dysphoric disorder (PMDD) constitute the core PMD.

Diagnosis of PMD can only be made after exclusion of physical and psychiatric disease, and relies mainly on the timing and severity of symptoms. PMD should also be differentiated from the simple premenstrual symptom that does not interfere with the daily functioning. A diagnostic

Received: $26^{\text {th }}$ August 2018. Accepted: $10^{\text {th }}$ October 2018.

Durairaj A, Ramamurthi R. Prevalence, pattern and predictors of premenstrual syndrome (PMS) and premenstrual dysphoric disorder (PMDD) among college girls. The New Indian Journal of OBGYN. 2019; 5(2): 93-8 
criterion for PMS was published by ACOG in 2000 and the American psychiatric association in 2013 has recommended PMDD diagnostic criteria in the Diagnostic and Statistical Manual of Mental Disorders (fourth edition) ${ }^{2}$.

Variation in the prevalence of PMD is due to the difference in the ethnicity, social and cultural background, diagnostic criteria and the study design. The prevalence of PMS among women is $30-40 \%$ and PMDD is $3-8 \%{ }^{3}$. Women with bothersome or distressing PMD often go undiagnosed or under treated. This is either because they don't report the symptoms to a clinician or the clinician has difficulty in diagnosing the disorder and in most situations an adequate response to their demand is not provided ${ }^{4}$.

PMD adversely affects education and daily life activities of college girls. As well defined diagnostic criteria and effective treatment are available now, timely recognition of this disorder will ensure individual well being and efficiency ${ }^{5,6}$. The aim of this study is to estimate the prevalence, pattern and predictors of PMS and PMDD among college girls and to assess the knowledge and attitude of college girls with PMS and PMDD with regard to the perception of premenstrual symptoms, physician consultation and treatment.

\section{Materials and Method}

A cross sectional questionnaire study was conducted among the undergraduate medical and engineering students. A total of 1189 students were approached. They were explained about the purpose and procedure of the study and the confidentiality was assured. Few first year engineering students felt uneasy and didn't take part in the study. Total 1112 number of students participated in the study were given a pretested questionnaire sheet in Tamil/English language.

The questionnaire sheet was divided under 3 sections. Section I included sociodemographic data, lifestyle details, menstrual history, medical illness and medications. Section II included premenstrual symptoms and the functional impairment caused by these symptoms based on a validated premenstrual syndrome screening tool (PSST). Section III included family history and perception of premenstrual symptoms, physician consultation and treatment.
PSST is a 19 item questionnaire, comprised of 14 premenstrual symptoms and 5 functional impairments. Participant rated their experience on these 19 items that appears in the week before menses and remits within few days after the onset of menses, during most of the cycles in the last 12 months, on a 4 point Likert scale.

Premenstrual symptom screening tool - scoring criteria

\section{Section I}

Mild Moderate Severe

1 - Anger/irritability

2 - Anxiety/tension

3 - Tearfulness

4 - Depressed mood

5 - Decrease interest in academic work

6 - Decrease interest in home

7 - Decrease interest in social activities

8 - Difficulty in concentrating

9 - Fatigue/lack of energy

10 -Over eating/food craving

11 - Insomnia

12 - Hypersomnia

13 - Feeling overwhelmed

14 - Physical symptoms (breast tenderness/swelling, headache, joint/muscle pain, bloating, weight gain)

Section II

Mild Moderate Severe

A - Interferes with education

B - Interferes with relationship of friends

C - Interferes with relationship of family

D - Interferes with social life activities

E - Interferes with house/hostel responsibility

The following criteria must be present for diagnosis of PMDD -

1. At least one of 1, 2, 3 or 4 in section I is severe.

2. In addition, at least four of $1-14$ in section I are moderate to severe.

3. At least one of A, B, C, D or E in section II is severe.

The following criteria must be present for diagnosis of moderate/ severe PMS -

1. At least one of $1,2,3$ or 4 in section I is moderate to severe.

2. In addition, at least four of $1-14$ in section I are moderate to severe.

3. At least one of A, B, C, D or E in section II is 
moderate to severe.

College students of age 17-25 years with regular menstrual cycle were included. Students with irregular menstrual cycle, medical disease like psychiatric illness, epilepsy, migraine and on medications like oral contraceptive pills, anxiolytics and antipsychotic drugs were excluded from the study.

Finally, 1047 students fulfilled the eligibility criteria. The collected data were analysed with IBM.SPSS statistics software 23.0 Version. To describe about the data descriptive statistics frequency analysis, percentage analysis were used. To find the significance in categorical data Chi-Square test was used.

\section{Results}

According to the PSST scoring criteria, the prevalence

Table 1: Prevalence of PMS and PMDD

\begin{tabular}{lll}
\hline Category & Frequency & Percent \\
\hline No/mild PMS & 858 & 81.9 \\
Moderate to severe PMS & 150 & 14.3 \\
PMDD & 39 & 3.7 \\
\hline
\end{tabular}

of moderate to severe PMS among the college students was $14.3 \%$ and PMDD was $3.7 \%$ (table 1). The pattern of symptomatology is shown in table 2. One thousand eighty four $(97.5 \%)$ of students reported atleast 1 premenstrual symptom and the commonest symptom was fatigue/lack of energy $(82.5 \%)$. In the moderate to severe PMS category, anger/irritability

Table 3: Analysis of pattern of functional impairment

\begin{tabular}{lllll}
\hline Functional impairment & $\begin{array}{l}\text { No/mild } \\
\text { PMS } \\
\text { n=858 (\%) }\end{array}$ & $\begin{array}{l}\text { Moderate to } \\
\text { severe PMS } \\
\mathbf{n = 1 5 0}(\mathbf{\%})\end{array}$ & $\begin{array}{l}\text { PMDD } \\
\mathbf{n = 3 9} \\
\mathbf{( \% )}\end{array}$ & P \\
\cline { 2 - 5 } College/work efficiency \\
or productivity & $262(30.5)$ & $124(82.66)$ & $39(100)$ & 0.0005 \\
Relationship with friends & $161(18.8)$ & $115(76.7)$ & $36(92.3)$ & 0.0005 \\
Relationship with family & $136(15.9)$ & $110(73.3)$ & $28(71.8)$ & 0.0005 \\
Social life activities & $198(23.0)$ & $107(71.3)$ & $32(82.0)$ & 0.0005 \\
Home responsibilities & $151(17.6)$ & $94(62.7)$ & $31(79.5)$ & 0.0005 \\
\hline
\end{tabular}
(96\%) was the commonest symptom, followed by fatigue/lack of energy (94.7\%) and physical symptoms (92\%). In the PMDD category, the commonest symptom was anxiety/tension (100\%), followed by fatigue/lack of energy (97.4\%) and difficulty in concentration (94.9\%).

The pattern of functional impairment among college girls is shown in table 3 . The most frequent functional impairment in the moderate to severe PMS and PMDD group was noted in college efficiency/productivity, which was reported by $82.7 \%$ and $100 \%$ of students respectively.

The predictors of PMS and PMDD among college girls is shown in table 4. The prevalence of PMS and PMDD correlated significantly with the mean age $>19$ years, medical education, heavy menstrual bleeding, dysmenorrhoea and family history of PMS. There was no statistically significant difference with respect to residence, socioeconomic status, age of menarche, days of menstrual bleeding, physical activity and basal metabolic index (BMI). 
Table 4: Analysis of predictors of PMS and PMDD

\begin{tabular}{|c|c|c|c|c|c|}
\hline \multicolumn{2}{|l|}{ Characteristics } & \multirow{2}{*}{$\begin{array}{l}\text { No/mild PMS } \\
\text { N=858 (\%) }\end{array}$} & \multirow{2}{*}{$\begin{array}{l}\text { Moderate to } \\
\text { severe PMS } \\
\mathrm{N}=150(\%)\end{array}$} & \multirow{2}{*}{$\begin{array}{l}\text { PMDD } \\
\text { N=39 (\%) }\end{array}$} & \multirow[t]{2}{*}{$\mathbf{P}$} \\
\hline & & & & & \\
\hline \multicolumn{2}{|l|}{ Mean age in years } & 19.02 & 19.29 & 19.67 & 0.002 \\
\hline \multirow[t]{2}{*}{ Education } & MBBS & $298(74.5)$ & $76(19.0)$ & $26(6.5)$ & \\
\hline & $\mathrm{BE}$ & $560(86.6)$ & $74(11.4)$ & $13(2.0)$ & 0.0005 \\
\hline \multirow[t]{2}{*}{ Residence } & House & $569(82.8)$ & $95(13.8)$ & $23(3.3)$ & \\
\hline & Hostel & $289(80.3)$ & $55(15.3)$ & $16(4.4)$ & 0.523 \\
\hline \multirow{3}{*}{$\begin{array}{l}\text { Socioeconomic } \\
\text { status }\end{array}$} & Upper & $65(84.4)$ & $9(11.7)$ & $3(3.9)$ & \\
\hline & Middle & $731(82.5)$ & $122(13.8)$ & $33(3.7)$ & \\
\hline & Lower & $62(73.80)$ & $19(22.6)$ & $3(3.6)$ & 0.251 \\
\hline \multicolumn{2}{|c|}{ Mean age of menarche } & 12.83 & 12.67 & 12.72 & 0.405 \\
\hline \multicolumn{2}{|c|}{ Mean days of bleeding } & 4.71 & 4.88 & 5.31 & 0.079 \\
\hline \multirow{3}{*}{$\begin{array}{l}\text { Amount of } \\
\text { bleeding }\end{array}$} & Reduced & $51(82.3)$ & $11(17.7)$ & $0(0.0)$ & \\
\hline & Moderate & $758(83.7)$ & $121(13.4)$ & $27(3.0)$ & 0.0005 \\
\hline & Heavy & $49(62.0)$ & $18(22.8)$ & $12(15.2)$ & \\
\hline \multirow[t]{2}{*}{ Dysmenorrhoea } & Absent & $382(88.0)$ & $44(10.1)$ & $8(1.8)$ & \\
\hline & Present & $476(77.7)$ & $106(17.3)$ & $31(5.1)$ & 0.0005 \\
\hline \multirow{2}{*}{$\begin{array}{l}\text { Regular physical } \\
\text { activity }\end{array}$} & Absent & $712(82.5)$ & $122(14.1)$ & $29(3.4)$ & \\
\hline & Present & $146(79.3)$ & $28(15.2)$ & $10(5.4)$ & 0.357 \\
\hline \multicolumn{2}{|c|}{ Mean Body mass index $(\mathrm{kg} / \mathrm{m} 2)$} & 21.38 & 21.99 & 21.73 & 0.437 \\
\hline \multirow{2}{*}{$\begin{array}{l}\text { Family history of } \\
\text { PMS }\end{array}$} & Absent & $657(86.0)$ & $89(11.6)$ & $18(2.4)$ & \\
\hline & Present & $201(71.0)$ & $61(21.6)$ & $21(7.4)$ & 0.0005 \\
\hline
\end{tabular}

Table 5: Analysis of knowledge and attitude towards PMS and PMDD

\begin{tabular}{llllll}
\hline Characteristics & & $\begin{array}{l}\text { No/mild } \\
\text { PMS } \\
\text { N=858 (\%) }\end{array}$ & $\begin{array}{l}\text { Moderate to } \\
\text { severe PMS } \\
\text { N=150 }(\%)\end{array}$ & PMDD & P \\
& & $812(84.1)$ & $131(13.6)$ & $23(2.4)$ & \\
\hline Perception of & Normal & No) & \\
premenstrual symptoms & Abnormal & $46(56.8)$ & $19(23.5)$ & $16(19.8)$ & .0005 \\
Consultation for & No & $786(83.3)$ & $125(13.2)$ & $33(3.5)$ & \\
premenstrual symptoms & Yes & $72(69.9)$ & $25(24.3)$ & $6(5.8)$ & 0.004 \\
Treatment for & No & $807(83.1)$ & $128(13.2)$ & $36(3.7)$ & \\
premenstrual symptoms & Yes & $51(67.1)$ & $22(28.9)$ & $3(3.9)$ & 0.001 \\
\hline
\end{tabular}

The prevalence of PMS and PMDD in our study was $14.3 \%$ and $3.7 \%$ respectively. This is in concordance with the study by Raval et al from western India and few more studies 7-10. However, two other studies from western India had found high prevalence rate and this could be due to inclusion of PG students and nursing staff ${ }^{11,12}$. The high prevalence rates reported from other countries can be attributed to the difference in ethnicity and sociocultural variables $^{13-18}$.

More than $90 \%$ of students reported atleast 1 premenstrual symptom in the study by Raval et al and Bakshani et al and this is similar to our results ${ }^{8,9}$. In the present study, the pattern of symptomatology is different between college girls with PMS, PMDD and college girls without PMS and PMDD and it also varied between studies. The commonest symptom in the college girls without PMS and PMDD reported in this

The attitude of college girls with PMS and PMDD is shown in table 5. Among the 189 students with moderate to severe PMS and PMDD, only $16.4 \%$ students had a physician consultation and $13.2 \%$ students took treatment.

\section{Discussion}

This study elucidates the prevalence, pattern and predictors of PMS and PMDD among college girls and their knowledge and attitude. study and by Raval et al was fatigue/lack of energy, while it was sadness and abdominal bloating in the study by Mishra et al and in the studies from Saudi Arabia and Turkey respectively ${ }^{8,11,14,15}$.

The commonest symptom reported in this study and few more studies in the PMS category was anger/irritability, while it was low mood and physical symptoms in the study by Bakshani et al and Balahaha et al respectively ${ }^{7-9,14}$. In this study and in the study by 
Raval et al, the commonest symptom reported in the more severe affective predominant PMDD group was anxiety/tension ${ }^{8}$.

Though there is difference in symptomatology pattern between various studies globally, the predominant functional impairment in both the PMS and PMDD group reported in this study and in several studies was interference in college efficiency ${ }^{7-9}$.

This study analysed the predictors of PMS and PMDD among college girls with respect to sociodemographic, menstrual and lifestyle variables. Mean age of the student $>19$ years correlated significantly with the prevalence of PMS and PMDD. Many studies have reported increased prevalence in older students ${ }^{7,10,14,15,17,18}$, but few studies had conflicting results ${ }^{8,9}$. This can be explained by increased academic stress and understanding of symptoms in older students.

Medical students had statistically significant increased prevalence of PMS and PMDD than the engineering students. Several non comparative studies have reported higher prevalence rate among medical students ${ }^{11,13-15,18}$. This could be either due to the difference in the knowledge of the disease or academic curriculum. On the contrary, Raval et al found highest prevalence in commerce students than medical and nursing students ${ }^{8}$. Residence either at hostel or house and socioeconomic status are not statistically significant in the prevalence of PMS and PMDD and this is in agreement with few other studies $^{9,17}$.

Our study couldn't find any association between age of menarche and days of menstrual bleeding. But few studies had found an association with early age of menarche ${ }^{8,14,17}$. However in the current study, heavy menstrual bleeding had a positive correlation with PMS and PMDD. Dysmenorrhoea had been consistently associated with PMS and PMDD in several studies including ours ${ }^{7,8,10,17,18}$.

Though many societies have recommended physical activity in the management of PMS, several studies including the present study had not found a correlation between physical activity and PMS ${ }^{8,11,17,19}$. Daley et al concluded that to make any evidence-based policy recommendation regarding the effectiveness of exercise, more high-quality research is required ${ }^{20}$. BMI had no statistically significant correlation with PMS and PMDD in the present study and in the study by Cheng et al and others ${ }^{8,16}$.

In the current study and in numerous other studies, family history of PMS had a strong correlation with prevalence of PMS and PMDD among the college girls ${ }^{7}$, $8,13-15,17$

In the current study, college girls had little knowledge about premenstrual disorder as majority of the students with PMS and PMDD didn't perceive their symptoms as abnormal. The health seeking behavior among college students is poor as only few students with PMS and PMDD had a physician consultation and treatment. This attitude of college girls is not only because of lack of knowledge of PMS among students but also among the parents and teachers to whom they approach initially for these symptoms ${ }^{21,22}$.

\section{Limitations}

First, though PSST is simple and brief, its retrospective nature poses recall bias. A prospective daily recording of premenstrual symptom aids in confirming the diagnosis but it carries a high non response rate. Second, the study selectively sampled only few colleges in the urban area. Third, possible undiagnosed chronic medical illness can act as confounding factor.

\section{Conclusion}

PMS and PMDD are prevalent among substantial proportion of college girls with significant negative influence on academic performance, emotional well being and behaviour. The pattern of premenstrual symptomatology is different between PMS, PMDD and in overall college students. The predictors of PMS and PMDD are age, education, heavy menstrual flow, dysmenorrhoea and family history of PMS. The knowledge and health seeking behavior of college students towards PMD are quite low. Strategies should be drawn and implemented for timely recognition and management of PMS and PMDD in college girls.

\section{Conflict of interest: None. Disclaimer: Nil.}

\section{References}

1.O'Brien PMS, Bäckström T, Brown C, Dennerstein L, Endicott J, Epperson CN, et al. Towards a consensus on diagnostic criteria, measurement and trial design of the 
premenstrual disorders: the ISPMD consensus. Arch Womens Ment Health. 2011 Feb;14(1):13-21

2.American Psychiatric Association. Diagnostic and Statistical Manual of Mental Disorders. 5th ed. Arlington, VA: American Psychiatric Association; 2013.

3.Ryu A, Kim TH. Premenstrual syndrome: A mini review. Maturitas. 2015 Dec; 82(4):436-40.

4.Lete I, Dueñas JL, Serrano I, Doval JL, Martínez-Salmeán J, Coll C, et al. Attitudes of Spanish women toward premenstrual symptoms, premenstrual syndrome and premenstrual dysphoric disorder: results of a nationwide survey. Eur J Obstet Gynecol Reprod Biol. 2011 Nov;159 (1):115-8.

5.Ismaili E, Walsh S, O'Brien PMS, Bäckström T, Brown C, Dennerstein L, et al. Fourth consensus of the International Society for Premenstrual Disorders (ISPMD): auditable standards for diagnosis and management of premenstrual disorder. Arch Womens Ment Health. 2016 Dec; 19(6):953958.

6.Royal College of Obstetricians and Gynaecologists (RCOG). Management of Premenstrual Syndrome (Greentop Guideline No. 48) [Accessed 10 May 2009]; 2007

7.Nisar N, Zehra N, Haider G, Munir AA, Sohoo NA. Frequency, intensity and impact of premenstrual syndrome in medical students. J Coll Physicians Surg Pak. 2008 Aug; 18(8):481-4

8.Raval CM, Panchal BN, Tiwari DS, Vala AU, Bhatt RB. Prevalence of premenstrual syndrome and premenstrual dysphoric disorder among college students of Bhavnagar, Gujarat. Indian J Psychiatry. 2016 Apr-Jun; 58(2):164-70.

9.Bakhshani NM, Mousavi MN, Khodabandeh G. Prevalence and severity of premenstrual symptoms among Iranian female university students. J Pak Med Assoc. 2009 Apr; 59(4):205-8.

10.Adewuya AO, Loto OM, Adewumi TA. Premenstrual dysphoric disorder amongst Nigerian university students: prevalence, comorbid conditions, and correlates. Arch Womens Ment Health. 2008; 11(1):13-8.

11. Mishra A, Banwari G, Yadav P. Premenstrual dysphoric disorder in medical students residing in hostel and its association with lifestyle factors. Ind Psychiatry J. 2015 JulDec; 24(2): 150-57.

12.Padhy SK, Sarkar S, Beherre PB, Rathi R, Panigrahi M, Patil PS. Relationship of premenstrual syndrome and premenstrual dysphoric disorder with major depression: relevance to clinical practice. Indian J Psychol Med. 2015 Apr-Jun; 37(2):159-64.

13.Farrokh-Eslamlou H, Oshnouei S, Heshmatian B, Akbari E. Premenstrual syndrome and quality of life in Iranian medical students. Sex Reprod Healthc. 2015 Mar; 6(1): 23-7.

14.Balaha MH, Amr MAEM, Moghannum MSA, Saab AMN. The phenomenology of premenstrual syndrome in female medical students: a cross sectional study. Pan Afr Med J. 2010; 5: 4.

15.Goker A, Artunc-Ulkumen B, Aktenk F, Ikiz N. Premenstrual syndrome in Turkish medical students and their quality of life. J Obstet Gynaecol. 2015 Apr; 35(3): 275-8.

16.Cheng SH, Shih CC, Yang YK, Chen KT, Chang YH, Yang YC. Factors associated with premenstrual syndrome - a survey of new female university students. Kaohsiung J Med Sci. 2013 Feb; 29(2):100-5.

17.Sahin S, Ozdemir K, Unsal A. Evaluation of premenstrual syndrome and quality of life in university students. J Pak Med Assoc. 2014 Aug; 64(8): 915-22.

18.Issa BA, Yussuf AD, Olatinwo AW, Ighodalo M. Premenstrual dysphoric disorder among medical students of a Nigerian university. Ann Afr Med. 2010 Jul-Sep; 9(3):11822 .

19.Kroll-Desrosiers AR, Ronnenberg AG, Zagarins SE, Houghton SC, Takashima-Uebelhoer BB, Bertone-Jhonson ER. Recreational Physical Activity and Premenstrual Syndrome in Young Adult Women: A Cross-Sectional Study. PLoS One. 2017 Jan 12; 12(1): e0169728.

20.Daley A. Exercise and premenstrual symptomatology: a comprehensive review. J Womens Health (Larchmt). 2009 Jun;18(6):895-9.

21.Dennerstein L, Lehert P, Heinemann K. Global study of women's experiences of premenstrual symptoms and their effects on daily life. Menopause Int. 2011 Sep;17(3):88-95.

22.Choi D, Lee DY, Lehert P, Lee IS, Kim SH, Dennerstein L. The impact of premenstrual symptoms on activities of daily life in Korean women. J Psychosom Obstet Gynaecol. 2010 Mar;31(1):10-5.2.

\footnotetext{
Anitha Durairaj ${ }^{1}$, Rathna Ramamurthi ${ }^{2}$

${ }^{1}$ Assistant professor; ${ }^{2}$ Professor; Department of Obstetrics and Gynaecology, Velammal Medical College Hospital and Research Institute, Madurai, Tamil Nadu, India.
} 